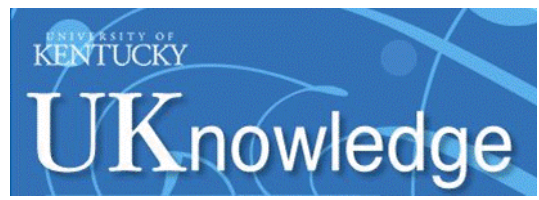

University of Kentucky

UKnowledge

Power and Energy Institute of Kentucky Faculty Publications

7-12-2018

\title{
Coreless and Conventional Axial Flux Permanent Magnet Motors for Solar Cars
}

\author{
Narges Taran \\ University of Kentucky, narges.taran@uky.edu \\ Vandana Rallabandi \\ University of Kentucky, vandana.rallabandi@uky.edu \\ Greg Heins \\ Regal Beloit Corporation, Australia \\ Dan M. Ionel \\ University of Kentucky, dan.ionel@uky.edu
}

Follow this and additional works at: https://uknowledge.uky.edu/peik_facpub

Part of the Power and Energy Commons

Right click to open a feedback form in a new tab to let us know how this document benefits you.

\section{Repository Citation}

Taran, Narges; Rallabandi, Vandana; Heins, Greg; and Ionel, Dan M., "Coreless and Conventional Axial Flux Permanent Magnet Motors for Solar Cars" (2018). Power and Energy Institute of Kentucky Faculty Publications. 28.

https://uknowledge.uky.edu/peik_facpub/28

This Article is brought to you for free and open access by the Power and Energy Institute of Kentucky at UKnowledge. It has been accepted for inclusion in Power and Energy Institute of Kentucky Faculty Publications by an authorized administrator of UKnowledge. For more information, please contact UKnowledge@lsv.uky.edu. 


\title{
Coreless and Conventional Axial Flux Permanent Magnet Motors for Solar Cars
}

\author{
Digital Object Identifier (DOI)
}

https://doi.org/10.1109/TIA.2018.2855123

\section{Notes/Citation Information}

Published in IEEE Transactions on Industry Applications, v. 54, issue 6.

(C) 2018 IEEE Copyright Notice. "Personal use of this material is permitted. Permission from IEEE must be obtained for all other uses, in any current or future media, including reprinting/republishing this material for advertising or promotional purposes, creating new collective works, for resale or redistribution to servers or lists, or reuse of any copyrighted component of this work in other works."

The document available for download is the authors' manuscript version that is accepted for publication. The final published version is copyrighted by IEEE and available as: N. Taran, V. Rallabandi, G. Heins and D. M. Ionel, "Coreless and Conventional Axial Flux Permanent Magnet Motors for Solar Cars,"IEEE

Transactions on Industry Applications, Vol. 54, No. 6, pp. 5907-5917, 2018. doi: 10.1109/TIA.2018.285512 


\title{
Coreless and Conventional Axial Flux Permanent Magnet Motors for Solar Cars
}

\author{
Narges Taran ${ }^{1}$, Vandana Rallabandi ${ }^{1}$, Greg Heins ${ }^{2}$, and Dan M. Ionel ${ }^{1}$ \\ ${ }^{1}$ Department of Electrical and Computer Engineering, University of Kentucky, Lexington, KY, USA \\ narges.taran@uky.edu, vandana.rallabandi@uky.edu,dan.ionel@uky.edu \\ ${ }^{2}$ Regal Beloit Corporation, Australia, Rowville, VIC, Australia, greg.heins@ regalbeloit.com
}

\begin{abstract}
Axial flux permanent magnet (AFPM) motors are suitable options for solar powered vehicles due to their compact structure and high torque density. Furthermore, certain types of APFM machines may be configured without stator cores, which eliminates associated losses and cogging torque and simplifies the manufacturing and assembly. This paper examines two machine designs for use in the solar powered vehicle of the challenger class-a single rotor, single stator conventional AFPM machine, and a coreless AFPM machine with multiple stator and rotor disks. Response surface methodology (RSM) is utilized for the systematic comparison of the conventional and coreless topologies and to select the optimum designs among several hundreds of candidates. Designs with minimum losses and mass producing required torque with larger air-gap are favored. The performance of the selected designs have been studied via 3D finite element analysis (FEA). The FEA parametric modeling methodology is validated by measurements on three AFPM machines of the conventional and coreless type.
\end{abstract}

Index Terms-Axial flux permanent magnet machines, coreless, multi-disk, solar powered electric vehicles, finite element analysis, winding factor, response surface methodology, design of experiments.

\section{INTRODUCTION}

A XIAL flux permanent magnet (AFPM) machines have attracted attention in numerous applications due to advantages including high specific torque, pancake type profiles, and flexible topology. In case of a double rotor structure configured such that PMs of opposite polarity face each other, magnetic flux from one rotor flows into the other without traveling circumferentially through the stator core, which may thus be eliminated, leading to the removal of associated loss and cogging torque, although at the cost of a higher electromagnetic air-gap.

Previously published papers have mostly focused on conventional AFPM machines, which include a feromagnetic core, e.g. [1]-[4]. Coreless AFPM machines have been studied less frequently. Some examples include the multiobjective optimal design of coreless AFPM machines, discussed in [5]-[7], fractional slot winding configurations [8], and applications of such machines in wind turbine generators, [9], [10], electric vehicles, [11], [12], and airplanes, [13], [14].

This paper is a follow-up expansion of the conference papers [15], [16] and brings contributions by conducting systematic comparative studies on in-wheel AFPM motor topologies. In case of the in-wheel (direct-wheel) drive systems, the motor is embedded inside the wheel, which offers the potential to Authors' manuscript version. The final published version is copyrighted by IEEE and availabl Flux Permanent Magnet Motors for Solar Cars," IEEE Transactions on Industry Applications, Vol. 54, No. 6, pp. 5907-5917, 2018. doi: 10.1109/TIA.2018.2855123. C2018 IEEE Copyright Notice. "Personal use of this material is permitted. Permission from IEEE must be obtained for all other uses, in any current or future media, including reprinting/republishing this material for advertising or promotional purposes, creating new collective works, for resale or redistribution to servers or lists, or reuse of any copyrighted component of this work in other works." eliminate some of the mechanical components, consiquently simplifying the system. The solar cars with three wheels, can be configured to have two front wheels and one rear driving wheel with the motor inside. The cars with four wheels can have two rear driving wheels. In this study, both cases are included. The machines considered for use in solar cars with one or two driving wheels are: a conventional single rotor-single stator core machine, based on a commercially available NGM SC-M150 motor [17] and a coreless multidisk configuration with air-gap concentrated windings. The comparative study is based on the design of experiments (DOE) and response surface methodology (RSM), and several thousand candidate designs for both types of machines are studied. During the course of the comparison, the main dimensions of both machines are maintained the same, to ensure that they accommodate inside the same wheel. The DOE and RSM techniques are used to observe the relative trend between performance parameters and select the best designs. The designs with minimum losses and mass, while meeting the required torque are selected. The performance calculation uses 2D and 3D finite element analysis (FEA), and the methodology is validated by measurements on a number of conventional and coreless machines.

Furthermore, the paper also discusses design aspects of coreless AFPM motors, including the effects of selection of number of poles, and number of stator-rotor disks. A method for calculating the winding factor for air-gap concentrated windings is proposed. An additional objective is to determine whether the required performance can be achieved at a higher mechanical air-gap in order to increase mechanical robustness. This has been taken into account in design selection.

The next section provides specifications of the reference model and theoretical design considerations. Section III includes a detailed approach to calculate the winding factor of the winding of coreless stator. A multi-disk coreless machine design procedure, including selection of number of disks, poles and coils is discussed in section IV. The response surface methodology, design variables and performance responses are introduced in section V. Afterwards, the selection of the best designs and their comparison, with further analysis is included. Section VII covers experimental validation for the numerical design and analysis study on commercially available motors for solar car applications and a special laboratory prototype of a multi-disk coreless machine. In the last section, a conclusion is provided.

as: N. Taran, V. Rallabandi, G. Heins and D. M. Ionel, "Coreless and Conventionat Axial 


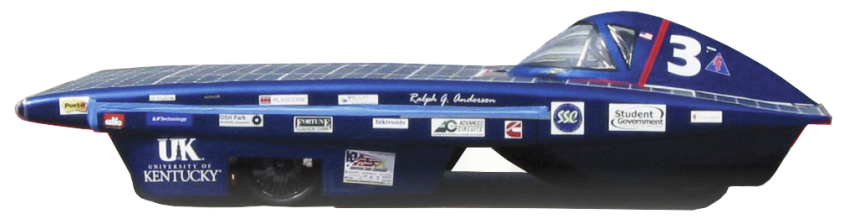

Figure 1. Gato del Sol IV solar car from University of Kentucky.

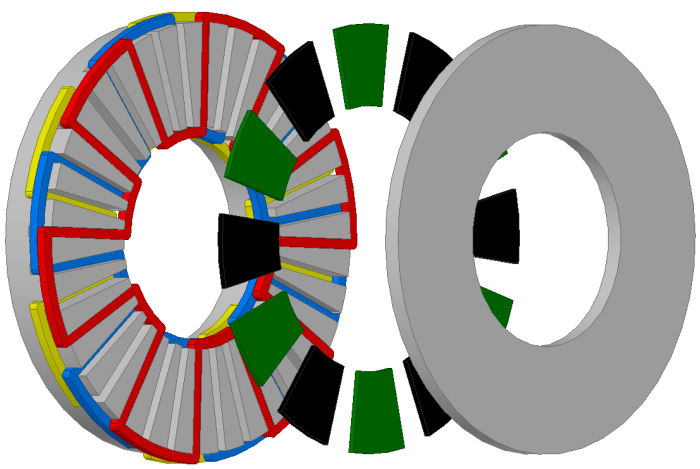

Figure 2. Exploded view of the 3D model of the NGM SC-M150 motor with 36 stator slots and 12 rotor poles.
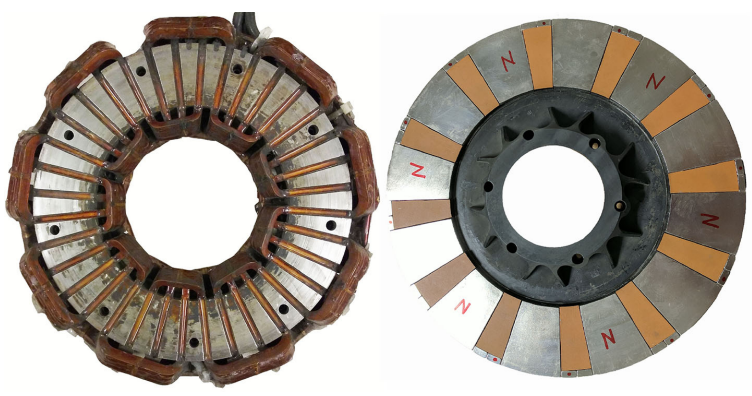

Figure 3. The stator of the NGM SC-M150 motor installed in Gato del Sol IV solar car together with a new prototype rotor.

\section{Solar Car Electric Motor Specifications}

The reference motor for this study is represented by the NGM SC-M150 unit that has been used in the Gato del Sol IV solar car at University of Kentucky, Fig. 1. This motor, which has a 36 slot stator core with distributed windings and a 12 pole rotor core with surface mounted PMs, has been modeled in 3D (Fig. 2), analyzed by the electromagnetic FEA, and a new PM rotor has been prototyped as part of the current study in order to match with the existent stator (Fig. 3).

The power system includes a solar panel connected to a boost converter performing the function of maximum power point tracking which feeds the 3 phase inverter driving the traction motor. A Li-ion battery is used to power the machine during shading, when high bursts of power are required, and also to absorb power during regenerative braking.

In addition to electromagnetic considerations, mechanical challenges of a small air-gap in AFPM motors should be taken into account. For a thinner air-gap, the smallest amount of arching of the axle, caused by unsprung mass, becomes problematic. Therefore, it is preferred to use the largest airgap possible while maintaining the performance parameters.
Table I

SPECIFICATIONS AND MAIN DIMENSIONAL PROPERTIES OF THE NGM SC-150 (CONVENTIONAL) AFPM MOTOR.

\begin{tabular}{lr}
\hline Rated Torque & $56 \mathrm{Nm}$ \\
Rated speed & $400 \mathrm{rpm}$ \\
Air gap & $1.8-5 \mathrm{~mm}$ \\
Active outer diameter & $248.0 \mathrm{~mm}$ \\
Total axial length & $52.5 \mathrm{~mm}$ \\
Steel mass & $11.2 \mathrm{~kg}$ \\
PM mass & $0.6 \mathrm{~kg}$ \\
Copper mass & $2.2 \mathrm{~kg}$ \\
Total active mass & $14.0 \mathrm{~kg}$ \\
Number of poles & 12 \\
Number of slots & 36 \\
Number of coils per phase & 6 \\
\hline
\end{tabular}

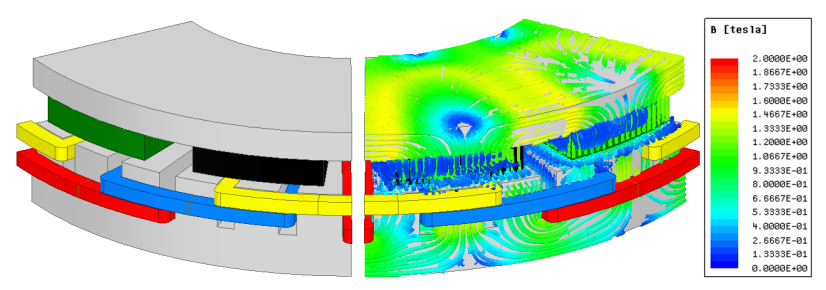

(a)
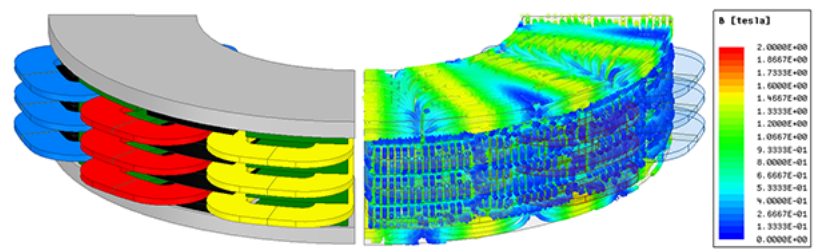

(b)

Figure 4. The 3D model and electomagnetic field for (a) the conventional, and (b) the coreless machines considered in the study.

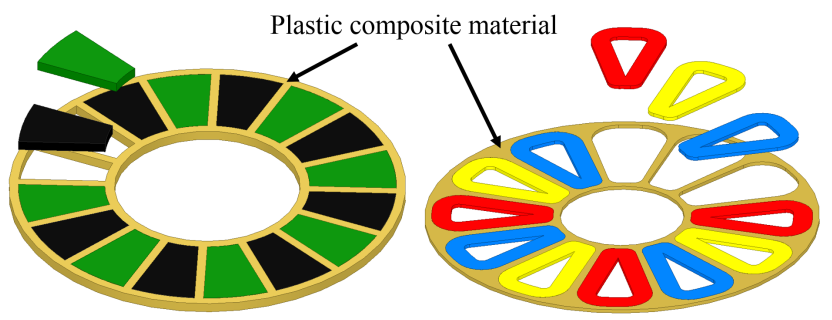

Figure 5. Schematic of a coreless stator and rotor employing a plastic composite structure for mounting and supporting magnets and coils.

The specification of the reference motor (Table I) limits airgap thickness between 1.8 to $5 \mathrm{~mm}$. One objective of this study is to re-design the NGM SC-150 machine, in order to meet the rated torque requirements with the largest possible air-gap, as well as minimum losses and mass.

Another objective is to design a coreless machine to be employed with two driving wheels in the same solar vehicle, with minimum loss and mass, and the largest feasible air-gap. The 3D model representation with flux lines and flux density distribution of both machines under study are illustrated in Fig. 4. In case of the coreless machine, the required mechanical support for the discs in the middle can be provided by ad- 


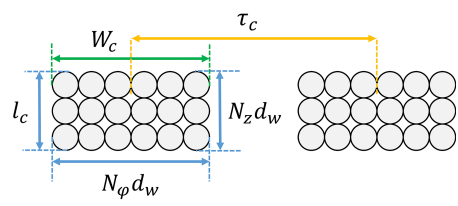

Figure 6. Radial cut-out of a concentrated coil.

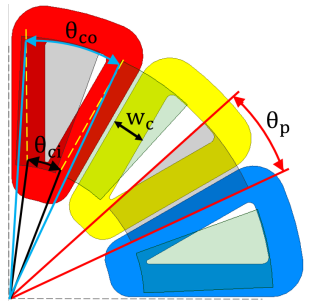

Figure 7. Coil pitch angle variation with diameter. The magnets are included in the plot and are transparent. vanced engineering composite plastic materials, as represented in Fig. 5. These materials have good thermal properties, low weight, and no extra losses [18] and [19].

In AFPM machines the torque is directly proportional to the cube of the diameter, hence, employing largest feasible diameter is recommended which is $248 \mathrm{~mm}$ and limited by the dimensions of the wheel. The yokes also perform as part of the frame of the wheel, therefore the total axial length is constant and dictated by the wheel dimensions.

\section{Winding FACTOR CALCULATION FOR AIR-GAP CONCENTRATED WINDING}

The fundamental winding factor is an index used to compare winding configurations. Elimination of stator core and slots results in removing mechanical constraints of positioning coil sides. For the coreless machine, concentrated windings are considered due to their shorter end coils, lower copper mass, and less manufacturing complexity as compared to the distributed winding.

Winding factor is defined as the ratio of the induced electromotive force (EMF) to the EMF that would have been induced in the ideal case. The ideal situation is considered where the induced EMF in all conductors have identical phases and maximum magnitude. In case of a conventional AFPM machine this is achieved for full-pitch, non-skewed winding, with one slot per pole per phase. For a non-skewed conventional machine, winding factor, $k_{w}$, can be represented by the product of pitch factor, $k_{p}$, and distribution factor, $k_{d}$. In case of a coreless machine, the coils are exposed to the continuously varying air-gap flux density. This causes the induced EMF in adjacent conductors, even in the same coil side, to have different phases from one another. Moreover, in the axial direction, conductors closer to PMs will have EMF with a higher magnitude. Such that only conductors at the closest layer to PMs have the maximum EMF. Therefore, additional distribution factors in circumferential and axial direction need to be taken into account. As explained in the following, the effect of phase shift between EMF of adjacent conductors is captured by $k_{d \phi}$ and the effect of varying magnitude by axial position is captured by $k_{d z}$.

So far, efforts in estimating winding factor for coreless machines has been executed with over-simplifications. Studies are conducted overlooking the distrbution factor in the axial

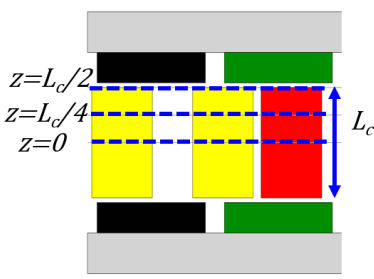

(a)

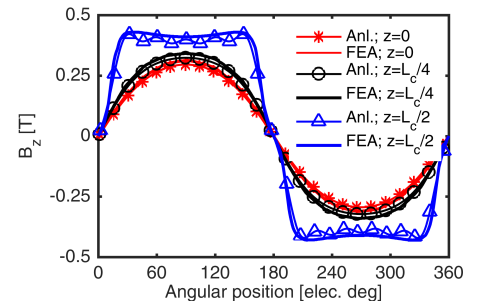

(b)
Figure 8. Analytical and numerical calculation of axial component of flux density at different axial positions for a 12 coil 16 pole single stator design.

direction or neglecting the gap between phase bands [14], [20], [21]. The calculations dedicated to linear coreless machines [22], [23] does not consider the variation of coil pitch to pole pitch ratio with respect to diameter which is the case for rotational AFPM coreless machines.

For a fractional-slot concentrated winding, in a machine with a slot pole combination such as 12-slot 8-pole or 24slot 16-pole, the distribution factor is unity. However, in case of airg-gap concentrated windings employed in coreless machines, the distribution factor within the same coil band, in the axial and circumferential directions, should be considered. The winding factor, $k_{w n}$, can be calculated as

$$
k_{w n}=k_{p} \cdot k_{d \phi} \cdot k_{d z},
$$

where $n$ is the harmonic order, and $k_{d \phi}$ and $k_{d z}$ are distribution factors in circumferential and axial direction, respectively.

Pitch factor: Considering a concentrated coil, with cylindrical cut at an arbitrary diameter represented in Fig. 6 and 7, the ration of the phasor sum to arithmetic sum of $n^{\text {th }}$ harmonic of the induced EMF in two coil sides can be estimated as

$$
k_{p}=\left|\frac{E-E e^{-j \frac{n \pi \tau_{c}}{\tau_{p}}}}{E+E}\right|=\sin \left(\frac{n \pi \tau_{c}}{2 \tau_{p}}\right) ; \quad \tau_{c}=\frac{\pi D}{N_{c}}-W_{c}
$$

where $\tau_{c}$ and $\tau_{p}$ are coil and pole pitch, $D$ is the diameter, $N_{c}$ number of coils per stator disk, and $W_{c}$ is the coil width. It is important to note that the ratio of coil pitch to pole pitch angle, $\frac{\theta_{c}}{\theta_{p}}$, varies with diameter, as shown in Fig. 7, resulting in varying $\frac{\tau_{c}}{\tau_{p}}$. Therefore, for an accurate estimation of pitch factor, integration of (2) from inner to outer diameter is performed. It can be shown that the maximum fundamental pitch factor is attained at $\frac{w_{c}}{\tau_{p}}=\frac{p}{N_{c}}-1$.

Distribution factor in the circumferential direction: For coreless machines with air-gap concentrated windings, distribution factor within the same coil band, in the circumferential direction, can be calculated as

$$
k_{d \phi}=\frac{\sin \left(\frac{\pi W_{c}}{2 \tau_{p}}\right)}{N_{\phi} \sin \left(\frac{\pi d_{w}}{2 \tau_{p}}\right)},
$$

where $d_{w}$ is the diameter of each conductor and $N_{\phi}$ is the number of turns in coil band in circumferential direction and 


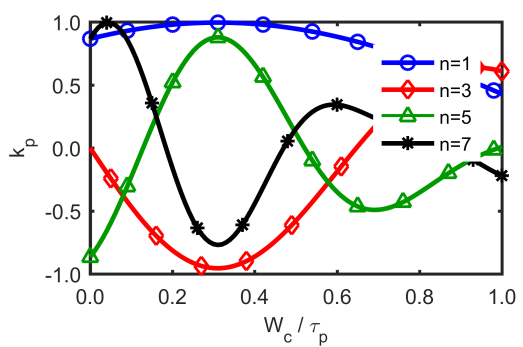

(a)

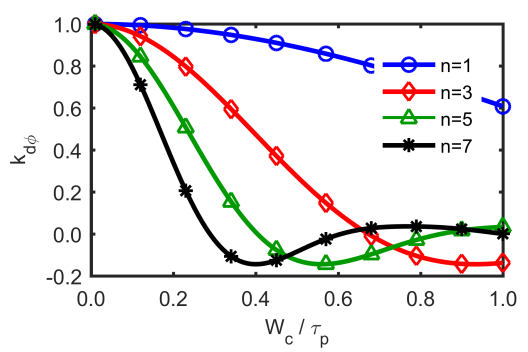

(b)

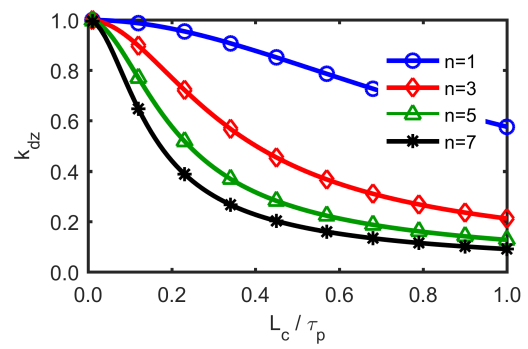

Figure 9. (a) Pitch factor, and (b) distribution factor in circumferential direction with respect to coil width to pole pitch ratio; and (c) distribution factor with respect to coil height to pole pitch ratio, plotted at different harmonics for a 16 pole 12 coil topology with concentrated coreless winding.

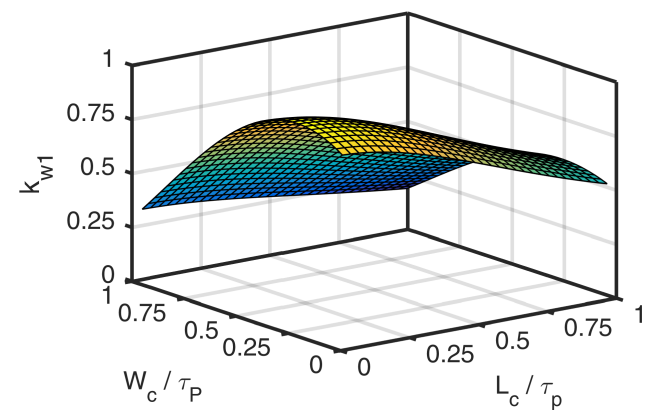

Figure 10. Fundamental winding factor for the 12 coil 16 pole topology.

can be estimated as $N_{\phi}=\frac{W_{c}}{d_{w}}$. In coreless winding the use of Litz wire with thin conductors is common, which results in

$$
d_{w} \approx 0 \rightarrow k_{d \phi}=\frac{2 \tau_{p}}{\pi W_{c}} \sin \left(\frac{\pi W_{c}}{2 \tau_{p}}\right) .
$$

Variation of $\tau_{p}$ with diameter should be taken into account through an integral form of (4). Larger $k_{d \phi}$ is expected to be obtained with smaller coil width.

Distribution factor in axial direction: The axial component of flux density in a coreless machines is a function of angular position, $\phi$, and axial position, $z$, such that a higher flux density is seen by conductors closer to PMs. This effect is more significant in case of a thicker coil and larger electromagnetic air-gap. The $z$ component of flux density can be obtained by

$$
B_{z}(\phi, z)=\sum_{n=1}^{\infty} B_{n} \cosh \left(\frac{n \pi}{\tau_{p}} z\right) \cos \left(n \phi \frac{p}{2}\right) .
$$

Detailed calculations of $B_{n}$ can be found in [22], [24]. Figure 8 represents that this analytical estimation of $B_{z}$ for an example design is in agreement with the numerical results obtained from FEA.

Based on (5) the winding factor in axial direction can be calculated from

$$
k_{d z}=\frac{2 \sum_{i=1}^{N_{z} / 2} \cosh \left(\frac{n \pi d_{w}}{2 \tau_{p}}(2 i-1)\right)}{N_{z} \cosh \left(\frac{n \pi L_{C}}{2 \tau_{p}}\right)}=\frac{\tanh \left(\frac{n \pi L_{C}}{2 \tau_{p}}\right)}{N_{z} \sinh \left(\frac{n \pi d_{w}}{2 \tau_{p}}\right)} .
$$

Considering that Litz wires are employed yields,

$$
d_{w} \approx 0 \rightarrow k_{d z}=\frac{2 \tau_{p}}{n \pi L_{c}} \tanh \left(\frac{n \pi L_{C}}{2 \tau_{p}}\right) .
$$

Again, due to diameter dependent $\tau_{p}$, integration of (7) should be considered.

The variation of winding factor components with respect to $\frac{W_{c}}{\tau_{p}}$ and $\frac{L_{c}}{\tau_{p}}$ at different harmonics, for a 16 pole 12 coil topology, is plotted in Fig. 9. The fundamental winding factor variation, illustrated in in Fig. 10, shows that largest winding factor is obtained when the coils are axially as thin as possible and the coil width is closer to $\left(\frac{p}{N_{c}}-1\right) \cdot \tau_{p}$.

\section{SpecificAtions AND DESign Considerations of THE CORELESS AFPM MOTOR}

The coreless machine is considered to be employed for a two-driving wheel application, therefore, each of the motors should produce half the required torque within the same outer dimensions (diameter and axial length) as the conventional machine.

\section{A. Selecting the Number of Disks}

The larger electromagnetic air-gap, caused by the elimination of stator core, reduces flux linkage and torque. This may be compensated for by the use of multiple disks. The use of multiple coreless stator disks also reduces the coil thickness, improving the winding factor by increasing the distribution factor in axial direction as shown in (7).

In order to evaluate the appropriate number of stator disksand accordingly the number of rotor disks - three models with one, two, and three stators are studied for an example coreless AFPM with 12 coils per stator disk and 16 poles. In the course of the comparison, the copper losses, air-gap, active volume, PM mass, and steel mass are kept constant.

The higher flux leakage and smaller winding factor for lower number of disks reduces torque density (Fig. 11 and Table II). The designs with multiple stator disks demonstrate significant performance improvement with higher winding factor. For those reasons, the design with three stators is selected, although it may be noted that a higher number of disks may lead to difficulties in the manufacturing process. 


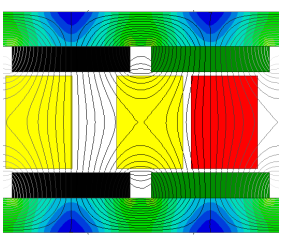

(a)

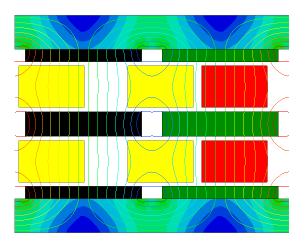

(b)

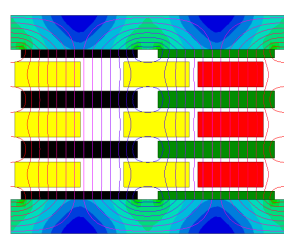

(c)
Figure 11. Magnetic flux lines for multi-disk AFPM machines with different number of disks.

\section{B. Selecting the Combination of Poles and Coils}

A wide array of number of stator coil and rotor pole combinations is possible for this machine, and the comparative performance of some representative ones is studied. The electromagnetic air-gap is maintained the same for all designs by keeping the axial thickness of the coils, $L_{c}$, constant during the comparison. The total PM and steel mass are also kept the same. The thickness of the rotor core is dictated by mechanical strength constraints, considering that back plates are also functioning as part of the frame.

A larger number of poles necessitates increasing number of coils to maintain a reasonable fundamental winding factor. For a diameter constrained application, the use of a large number of coils results in reduced coil width and end turn volume such that the total copper mass reduces. This can be quantified by estimating the mean turn length, $\mathfrak{l}_{m t}$,

$$
\mathfrak{l}_{m t}=\left(D_{o}-D_{i}\right)+\frac{\pi\left(D_{o}+D_{i}\right)}{N_{c}}, \text { and } W_{c}=\frac{\pi D_{i}}{2 N_{c}},
$$

where $D_{o}$ and $D_{i}$ are the outer and inner active diameter. Coil width, $W_{c}$, is constrained by inner diameter and is set on maximum possible value to reduce current density and improve DC copper loss. The total copper volume for 3 stator disks is calculable by

$V_{c}=3 N_{c} W_{c} L_{c} L_{m t}=\frac{3 \pi D_{i}}{2} L_{c}\left[\left(D_{o}-D_{i}\right)+\frac{\pi\left(D_{o}+D_{i}\right)}{N_{c}}\right]$

where $V_{c}$ is the copper volume. Thus, in the case of a constant fill factor, as $N_{c}$ increases, $V_{c}$ and consequently mass decrease.

Core losses in air-cored machines are small considering that steel is only used in the rotor. These losses can be further reduced and made negligible by approaches such as multi-layer windings that significantly decrease harmonics that only cause losses [25]. For those reasons, core losses are not accounted for in this comparison.

Litz wire is used to prevent skin effects at higher frequency, which can be quite substantial for this machine. Using such special conductor wires reduces the fill factor, and a $20 \%$ reduction is considered in the study. Assuming $120^{\circ} \mathrm{C}$ maximum winding temperature, increased copper resistance due to temperature rise is taken into account.

The electromagnetic torque of a non-salient AFPM machine can be estimated as

$$
T=\frac{3}{2} \frac{p}{2} \lambda_{m} I ; \quad \lambda_{m}=\frac{2}{\pi} k_{w 1} N_{t} k_{v g} \alpha_{i} B_{g o} \tau_{p} L_{F e},
$$

Table II

TORQUE DENSITY AND FUNDAMENTAL WINDING FACTOR FOR 16 POLE 12 COIL TOPOLOGY WITH DIFFERENT NUMBER OF STATOR DISKS.

\begin{tabular}{l|rrr}
\hline Number of stator disks & 1 & 2 & 3 \\
\hline Torque density $[\mathrm{Nm} / \mathrm{kg}]$ & 2.5 & 2.9 & 3.0 \\
Winding factor & 0.680 & 0.826 & 0.860 \\
\hline
\end{tabular}

Table III

ALL THE DESIGNED MACHINES PRODUCE 28 NM AT 400 RPM.

\begin{tabular}{l|rrrrrr}
\hline Poles & 8 & 10 & 16 & 20 & 30 & 32 \\
Coils & 6 & 6 & 12 & 12 & 18 & 24 \\
$k_{w 1}$ & 0.877 & 0.833 & 0.860 & 0.810 & 0.776 & 0.805 \\
Cu mass [kg] & 3.9 & 3.9 & 2.7 & 2.7 & 2.2 & 2.0 \\
Cu loss [W] & 288 & 305 & 221 & 239 & 245 & 236 \\
Elec. eff. [\%] & 86 & 85 & 89 & 88 & 88 & 88 \\
\hline
\end{tabular}

where $p$ is pole number; $\lambda_{m}$, magnetizing flux linkage produced by PMs; $N_{t}$, number of turns per phase, which is constant for all the designs in Table III; $k_{v g}$, the ratio of the amplitude of the fundamental wave to the average value of the air-gap flux density; $\alpha_{i}$, pole arc to pole pitch ratio; $B_{g o}$, the peak value of the open-circuit flux density; $\tau_{p}$, pole pitch; and $L_{F e}$, the core length. As the number of poles and coils increases, $\lambda_{m}$ decreases, mainly due to reduced flux collecting area proportional to the pole arc, and partly because of higher leakage. Magnetizing flux linkage reduction due to lower $\tau_{p}$ is negated by higher number of poles while $\lambda_{m}$ reduction due to increased leakage is compensated for by increasing current to produce constant torque.

The copper losses, $P_{c u}$, can be calculated from

$$
R_{p h}=\frac{L_{m t} N_{t}}{\sigma W_{c} L_{c} S_{f f} / N_{t}}, P_{c u}=3 R_{p h} I_{r m s}^{2}=\frac{V_{c} J^{2} F_{f}}{\sigma},
$$

where $R_{p h}$ is the resistance of one phase winding; $\sigma$, is the copper conductivity; and $F_{f}$ is the fill factor. Decrease in copper mass, due to reduction in the length of mean turn, and increase in $\mathrm{J}$, to produce $28 \mathrm{Nm}$, results in minimum copper loss for 16 and 20 pole designs. The topology with 16 poles has higher winding factor. Other benefits of this topology are avoiding manufacturing complexities associated with higher number of poles, and relatively low copper mass. Therefore 16 pole and 12 coil topology is selected to be a good compromise. It is to be noted that for designs with space limitations, a higher number of poles will result in reduced total diameter due to decreased thickness of end coils.

\section{Design of Experiments And Response Surface METHODOLOGY}

Response surface methodology (RSM) is essentially a particular set of mathematical and statistical methods used to aid in finding a particular solution for a system in which several input variables influence the performance. The input variables (factors) need to be independent of each other. The performance of the system can be measured by output parameters (responses) as a function of factors. The observed 


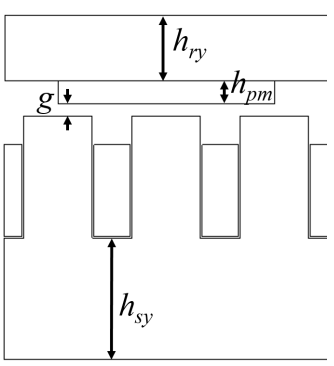

(a)

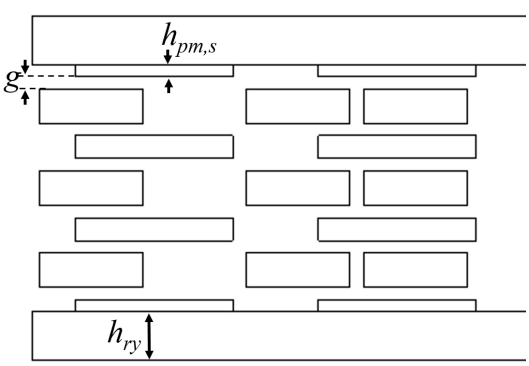

(b)
Figure 12. Dimensional variables selected as factors for DOE of (a) conventional, (b) coreless machine. The factors defined as ratios, i.e. tooth width to slot pitch ratio and pole arc to pole pitch ratio, are not included.

Table IV

GEOMETRICAL INPUT VARIABLES FOR THE PARAMETRIC MODEL OF THE CONVENTIONAL (CORED) MACHINE.

\begin{tabular}{llrr}
\hline Factor & Unit & Minimum value & Maximum value \\
\hline$x_{1}=g$ & $\mathrm{~mm}$ & 1.8 & 5.0 \\
$x_{2}=h_{p m}$ & $\mathrm{~mm}$ & 3.0 & 10.0 \\
$x_{3}=k_{t w}$ & & 0.35 & 0.65 \\
$x_{4}=\alpha$ & & 0.65 & 0.85 \\
$x_{5}=h_{s y}$ & $\mathrm{~mm}$ & 9 & 18 \\
$x_{6}=h_{r y}$ & $\mathrm{~mm}$ & 5 & 11 \\
\hline
\end{tabular}

Table $\mathrm{V}$

GEOMETRICAL INPUT VARIABLES FOR THE PARAMETRIC MODEL OF THE CORELESS MACHINE.

\begin{tabular}{lcrr}
\hline Factor & Unit & Minimum value & Maximum value \\
\hline$x_{1}=g$ & $\mathrm{~mm}$ & 0.5 & 2.0 \\
$x_{2}=h_{p m, s}$ & $\mathrm{~mm}$ & 1.0 & 3.5 \\
$x_{3}=\alpha$ & & 0.65 & 0.85 \\
$x_{4}=h_{r y}$ & $\mathrm{~mm}$ & 4.0 & 8.0 \\
\hline
\end{tabular}

trends can be employed to select an optimum design. A second order regression model (response surface), relating the factors to the output parameters is expressed as a polynomial function,

$Y=\beta_{0}+\sum_{i=1}^{d_{\nu}} \beta_{i} X_{C i}+\sum_{i=1}^{d_{\nu}} \beta_{i i} X_{C i}^{2}+\sum_{i=1}^{d_{\nu}} \sum_{j=i+1}^{d_{\nu}} \beta_{i j} X_{C i} X_{C j}$,

where $Y$ is a response; $\beta$ regression coefficient; $d_{\nu}$ number of factors, and $X_{C i}$ is normalized value of the $i^{\text {th }}$ factor.

The objectives to be met in case of both conventional and coreless topologies are to achieve least mass, and losses while producing the required torque at the rated speed. It is assumed that cost is not a constraint.

Six independent factors, that considerably influence the performance of the conventional motor, are selected (Fig. 12a and Table IV), including: the mechanical air-gap, $g$, PM length, $h_{p m}$, tooth width to slot pitch ratio, $k_{t w}$, pole arc to pole pitch ratio, $\alpha$, stator yoke length, $h_{s y}$, and rotor yoke length, $h_{r y}$. The outer and inner diameter, and total axial length are maintained the same as in the reference motor, limited by the wheel dimensions. In order to capture

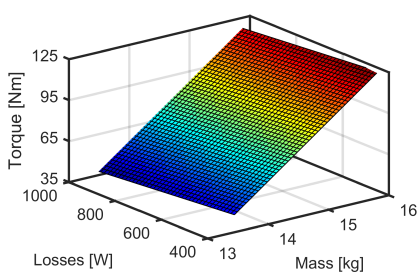

(a)

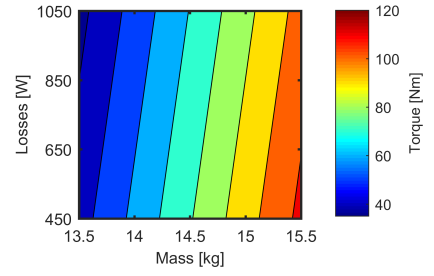

(b)
Figure 13. The responses of the conventional machine obtained from central composite DOE. (a) Three-dimensional plot and (b) the contour illustrating the responses relative performance.

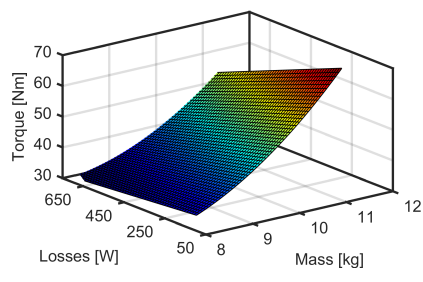

(a)

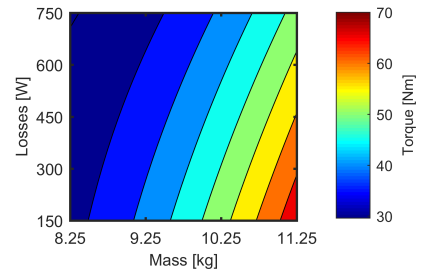

(b)
Figure 14. The responses of the multi-disk coreless machine obtained from full factorial DOE. (a) Three-dimensional plot and (b) the contour illustrating the responses relative performance.

the non-linearities associated with the response surface, 3 levels for each factor are considered. A full factorial design for 6 factors with 3 levels requires 729 runs which is not feasible. Instead, fractional factorial, Box-Behnken, or Central Composite designs may be used. Box-Behnken design requires less runs however it contains regions with poor prediction quality. Central Composite design provides relatively high quality predictions over the entire design space. For this case, face central composite design, with 6 factors and 3 levels, that needs only 100 runs, has been used. The FEA evaluations of these designs have been used to establish a regression model and then study above 4,000 designs.

In case of the coreless machine having no stator core or teeth, the number of factors is reduced to four, including the mechanical air-gap, $g$, the PM length on the rotor disks on two sides, $h_{p m, s}$, the pole arc to pole pitch ratio, $\alpha$, and the stator yoke length, $h_{s y}$, as described in Table V and Fig. 12b. The PM length in the middle rotor disks $h_{p m, m}$, is set to be twice that in the ends, which results in higher torque. Due to the lower number of factors, full factorial DOE with the number of levels increased to 4 is employed. This requires 256 designs to be evaluated by FEA which is affordable. A full factorial design provides higher quality regression model.

\section{Selection of Best Designs}

The result of DOE is used to fit a second order regression model for the responses including torque, mass, and losses (core and copper). In both cases, conventional and coreless machine, the overall volume is constant across all designs. Larger mass is a result of less space occupied by air, i.e. lower air-gap thickness, thicker magnets, more lamination, 
Table VI

REFERENCE MODEL AND SELECTED DESIGNS FOR THE CONVENTIONAL MOTOR, AT 400 RPM, FOR APPLICATION WITH ONE DRIVING WHEEL.

\begin{tabular}{|c|c|c|c|c|c|c|c|c|}
\hline & \multirow{2}{*}{$\begin{array}{r}\text { Reference } \\
\text { 3D FEA }\end{array}$} & \multicolumn{2}{|c|}{ Design 1} & \multicolumn{2}{|c|}{ Design 2} & \multicolumn{3}{|c|}{ Design 3} \\
\hline & & Regression & 2D FEA & Regression & 2D FEA & Regression & 2D FEA & 3D FEA \\
\hline Air-gap [mm] & 1.80 & - & 2.76 & - & 2.76 & - & 2.76 & 2.76 \\
\hline Torque $[\mathrm{Nm}]$ & 54.3 & 57.2 & 63.5 & 57.6 & 59.9 & 58.8 & 60.9 & 58.2 \\
\hline Active mass $[\mathrm{kg}]$ & 12.2 & 14.1 & 13.7 & 14.1 & 13.4 & 14.01 & 13.2 & 11.5 \\
\hline Core loss [W] & 14 & - & 19 & - & 17 & - & 20 & 18 \\
\hline Copper loss [W] & 398 & - & 325 & - & 319 & - & 302 & 351 \\
\hline Total losses [W] & 411 & 423 & 343 & 452 & 336 & 450 & 322 & 369 \\
\hline Cogging torque $[\mathrm{Nm}]$ & 13.8 & - & 21.8 & - & 11.9 & - & 5.5 & 6.9 \\
\hline Goodness $[\mathrm{Nm} / \sqrt{W}]$ & 2.7 & - & 3.5 & - & 3.3 & - & 3.4 & 3.0 \\
\hline
\end{tabular}

Table VII

FEA RESULTS OF THE SELECTED DESIGNS FOR THE CORELESS MOTOR FOR APPLICATION WITH TWO DRIVING WHEELS, AT THE RATED SPEED OF 400 RPM. ALL DESIGNS HAVE MECHANICAL AIR-GAP OF 1.85 MM.

\begin{tabular}{l|rrr|r}
\hline & \multicolumn{3}{|c}{ 2D FEA } & 3D FEA \\
& D1 & D2 & D3 & D1 \\
\hline Torque $[\mathrm{Nm}]$ & 28.7 & 29.5 & 28.3 & 27.3 \\
Active mass $[\mathrm{kg}]$ & 9.4 & 8.8 & 9.0 & 10.5 \\
Copper losses $[\mathrm{W}]$ & 168 & 215 & 332 & 168 \\
Goodness $[\mathrm{Nm} / \sqrt{W}]$ & 2.2 & 2.0 & 1.6 & 2.1 \\
\hline
\end{tabular}

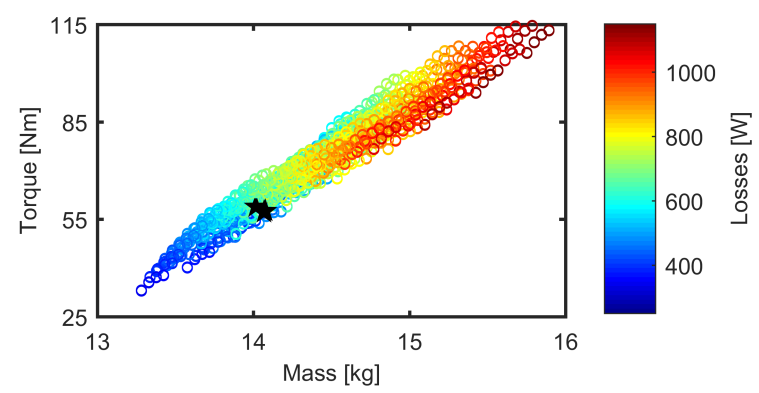

(a)

Figure 15. Projection of the DOE results and selected designs for the conventional motor. Designs marked with $\star$ are selected in order to have approximately the same torque as the reference machine and minimum losses.

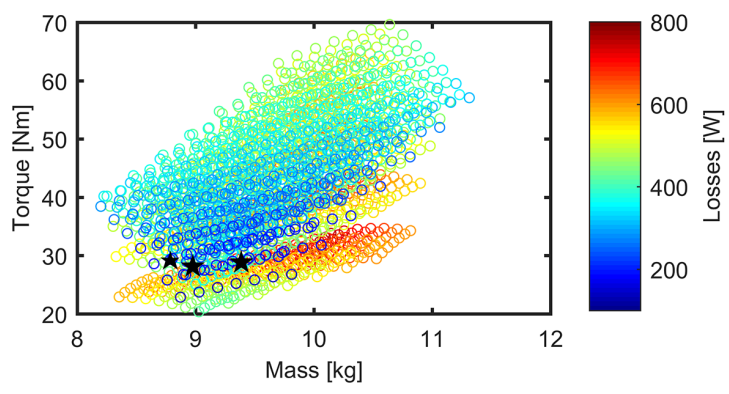

(a)

Figure 16. Projection of the DOE results and selected designs for the coreless motor. Designs marked with $\star$ are selected in order to have half the torque of the reference machine and minimum losses and mass.

and/or more copper. All of these increase losses as well as the produced electromagnetic torque (Figs. 13 and 14).

The regression model results compared to FEA for selected designs (Table VI) show at most $6 \%$ error for mass estimation by regression model, $10 \%$ error for torque estimation, and $39 \%$ error for loss estimation. The errors may have been caused by the reduced number of designs and levels and also considering that core loss is more nonlinear, hence requires more levels. These errors can be addressed by using a correction factor in the regression model's estimations. Nevertheless, the main function of RSM, that is to identify the trends, is achieved.

Based on the regression models, hundreds of designs are studied. For each of two motors, three designs are selected to be analyzed in more detail via 2D FEA. The objectives are to produce the rated torque with the lowest mass and losses. The selected designs are marked in the scatter plots (Fig. 15). In case of the conventional machine, for the desired torque the active mass ranges between $13.6 \mathrm{~kg}$ and $14.2 \mathrm{~kg}$ while losses range between $400 \mathrm{~W}$ and $700 \mathrm{~W}$. Designs with lower loss are assigned higher priority than those with lower mass.

The goodness of three selected designs, defined as $\frac{\text { Torque }}{\sqrt{\text { losses }}}$, are comparable. Design 3, being lighter with least losses, is selected to represent the conventional machine. Threedimensional FEA is used for a more reliable performance estimation (Fig. 4a). For this design, the AC losses, including eddy current and proximity, are analytically estimated [26] to be $0.57 \mathrm{~W}$ at $400 \mathrm{rpm}$. Therefore, for this machine at rated speed, the AC losses are insignificant compared to the total losses and neglected.

Design 3, with an air-gap of $2.76 \mathrm{~mm}$, achieves better performance than the reference design, which has a smaller air-gap of $1.85 \mathrm{~mm}$ (Table VI). Therefore, the required torque can be met with a larger air-gap and without compromising the performance.

The process is repeated for the coreless machine and three designs meeting the torque requirements have been selected (Fig. 16). The designs with lowest mass and loss are selected.

Due to the high quality of the full factorial DOE, and also robustness of coreless machines, the regression model's prediction of performance almost exactly matches that of 2D FEA. To avoid redundancy, only FEA results are presented in Table VII. The coreless motors have no cogging torque and their rotor core losses compared to copper losses are negligible. Comparing the goodness of the three selected designs, it is seen that Design 1 is superior to the others, and is thus selected. For this design it was analytically estimated [26] that using Litz wire with 40 strands per turn the winding AC losses are about $2.2 \mathrm{~W}$ and neglected. 


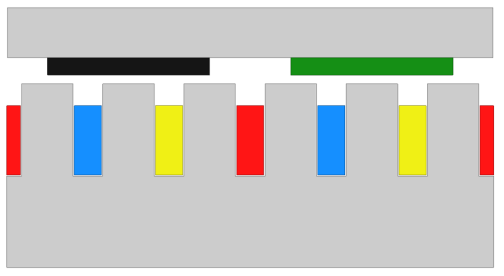

(a)

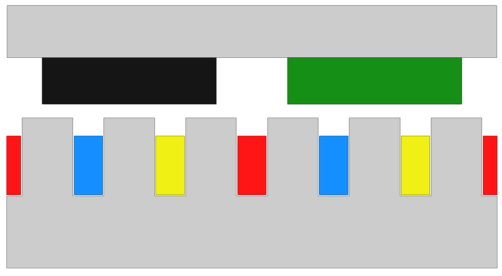

(b)

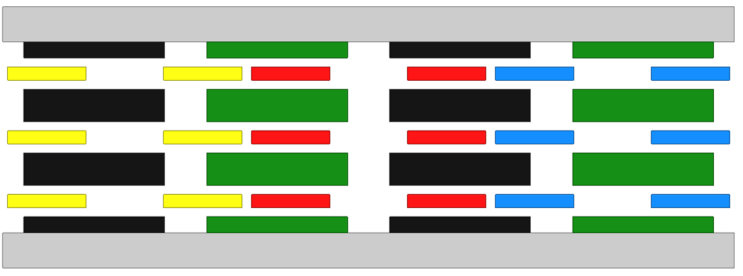

(c)

Figure 17. (a) The reference design, (b) the selected design 3 of conventional machine, (c) the selected design 1 of coreless machine. Taking advantage of the symmetrical geometry, only $\frac{1}{6}^{\text {th }}$ of the conventional machine and $\frac{1}{4}^{\text {th }}$ of the cored machine have been analyzed.

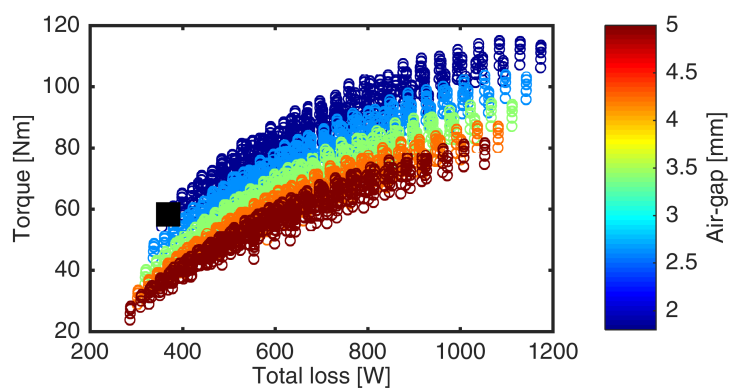

Figure 18. Conventional AFPM machine designs with changing air-gap. The selected design 3 in Table VI is marked with

An illustration of the contrast between dimensional properties of the reference model and the best designs of conventional and coreless motors is provided in Fig. 17. The 3D model of the selected best machines, i.e. design 3 of Table VI and design 1 of Table VII, are in fact the designs presented in Fig. 4.

\section{Discussion AND EXPERIMENTAL VALIDATION}

On comparing the selected design of the conventional AFPM with the best design of the coreless machine, the combined weight of the two motors for the latter is higher, i.e. $10.5 \times 2=21 \mathrm{~kg}$ compared to $11.5 \mathrm{~kg}$, for the conventional machine. However, in a two-wheel application, the mass is distributed between two wheels which reduces the pressure and also provides a better balance.

At the rated speed, the goodness of the conventional motor is higher than that of the coreless motor, presented in Tables VI and VII. Nevertheless, at higher speeds, core losses increase in the conventional machine. In the coreless machine, the only steel employed is in the rotor back iron. The losses in magnets and steel, caused by harmonics in the stator MMF, are negligible because of the absence of slots. Thus, the rotor losses are insignificant. At higher speeds the rotor loss may be reduced by special winding techniques [25], not applicable for conventional configurations with slotted stator. As explained in the previous section, in the coreless machine, the conductor AC loss are mitigated by the use of Litz wire and transposition. At higher speeds, for the conventional design, considerable core losses increase is observed. Thus, the coreless machine may in fact outperform the conventional machine.

One of the objectives of the study is to achieve designs with larger air-gap in order to mitigate the mechanical problems

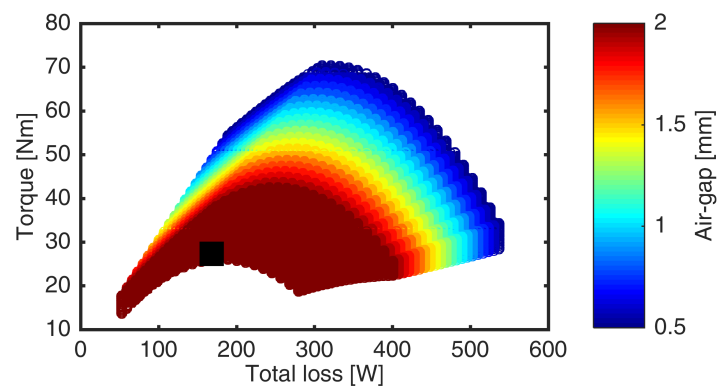

Figure 19. Coreless AFPM machine designs with changing air-gap. The selected design 1 in Table VII is marked with

associated with unsprung mass and arched axle. In the conventional AFPM, the required torque can be met with a larger air-gap than used in the commercially available machine. The impact of the air-gap on torque and losses for both configurations, illustrated in Fig. 18 and 19, shows for the desired torque production of the conventional machine, a larger air-gap results in considerable increase in the losses. Therefore, the selected design has a smaller air-gap in order to maintain an acceptable efficiency.

For the coreless machine design study, increasing the current beyond a threshold does not result in proportionally increased torque. This could be explained starting from the fact that the current density was fixed at $6.5 \mathrm{~A} / \mathrm{mm} 2$. It should be noted that, in principle, the study can be further expanded to consider specific cooling systems and particular thermal aspects, as discussed for example in [27]. In solar car applications, the motors are generally high efficiency for their volume such that the heat generated per volume is low and the thermal issues of a coreless machine design can be controlled.

In the current study, in order to increase the current, more copper wire is required to be used within the same geometrical envelope, which can be achieved, for example, by reducing the PM thickness, i.e. length in the direction of magnetization, which in turn results in decreased air-gap flux such that the electromagnetic torque does not increase although the current is higher. The selected design produces the required torque while attaining a relatively large air-gap and low losses (see Fig. 19).

The coreless machine is generally lighter than the conventional one. This makes coreless machine suitable for vehicles with two driving wheels, as the total active mass in this case doubles, and conventional machines suitable for single in- 

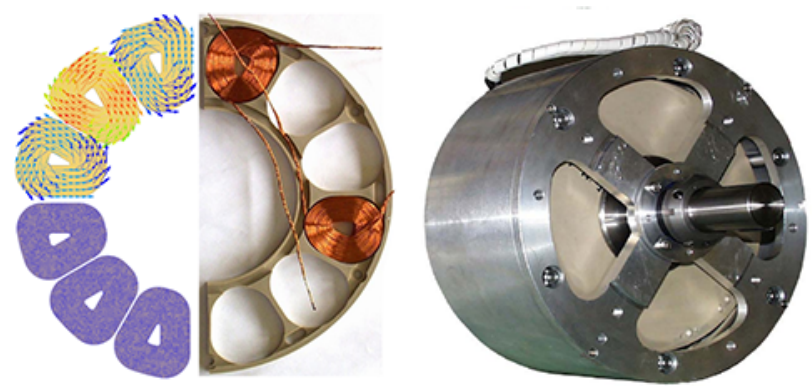

Figure 20. Special concentrated-winding multi-disk laboratory prototype employed for validating the 3D FEA parametric design study. The detailed fine finite element mesh and current density vectors in the coils calculated from 3D FEA are represented on the left.

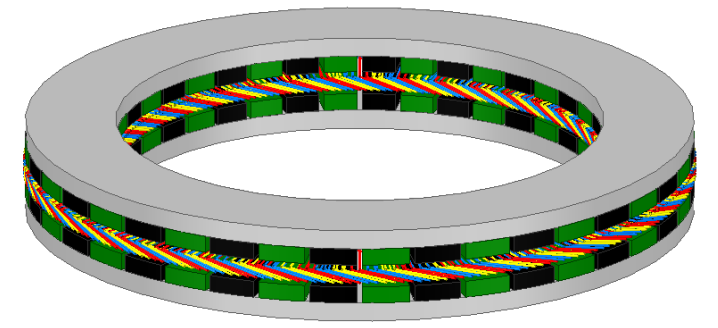

Figure 21. The 3D model of the commercially available distributed winding coreless AFPM machine produced by MARAND for in-wheel drive solar cars.

wheel application, for the same reason. The coreless machine may also be selected for the single in-wheel application, however, the mechanical air-gap needs to be very small, below $1 \mathrm{~mm}$, which is mechanically challenging, difficult to achieve and maintain. Utilizing conventional machines in double wheel vehicle results in much larger accumulated mass of rotors, on the other hand, considerably larger air-gaps could be used.

The design study based on electromagnetic 3D FEA has been validated with experimental data from a special concentrated-winding multi-disc laboratory prototype, which is shown in Fig. 20, and from two commercially available conventional and coreless AFPM machines, NGM and Marand, respectively, for solar powered vehicles. Marand topology has distributed air-cored winding and is represented in Fig. 21. NGM is the reference design and discussed in more detail in preceding sections. The main data for these machines is summarized in Table VIII and further details are available in [17], [19], [28], [29].

The experimental measurements and FEA results correlate favorably for the reference machines as illustrated in Fig. 22. The Marand machine is larger in active diameter and shorter in axial length. Considering that for axial flux machines the power is proportional to the cube of diameter, it is expected that Marand outperforms the NGM and all the other coreless machines designed for the dimensional limits similar to NGM. Also, Marand is benefited from distributed winding that improves its torque production capability.

It is observed that the coreless machine is distinctly lighter than the conventional design, and has lower loss, making it a better alternative for the double wheel configuration. The back iron portions of the rotors are also part of the wheel frame,
Table VIII

MAIN SPECIFICATIONS OF THE REFERENCE MACHINES CONSIDERED FOR THE EXPERIMENTAL VALIDATION OF THE 3D FEA STUDY.

\begin{tabular}{ll|rrr}
\hline & & Multi-disk coreless & Marand & NGM \\
\hline Speed & {$[\mathrm{rpm}]$} & 1000 & 1060 & 400 \\
Diameter & {$[\mathrm{mm}]$} & 290 & 312 & 248 \\
Axial length & {$[\mathrm{mm}]$} & 59 & 44.9 & 52.5 \\
Rated torque & {$[\mathrm{Nm}]$} & 21 & 16.2 & 56 \\
\hline
\end{tabular}

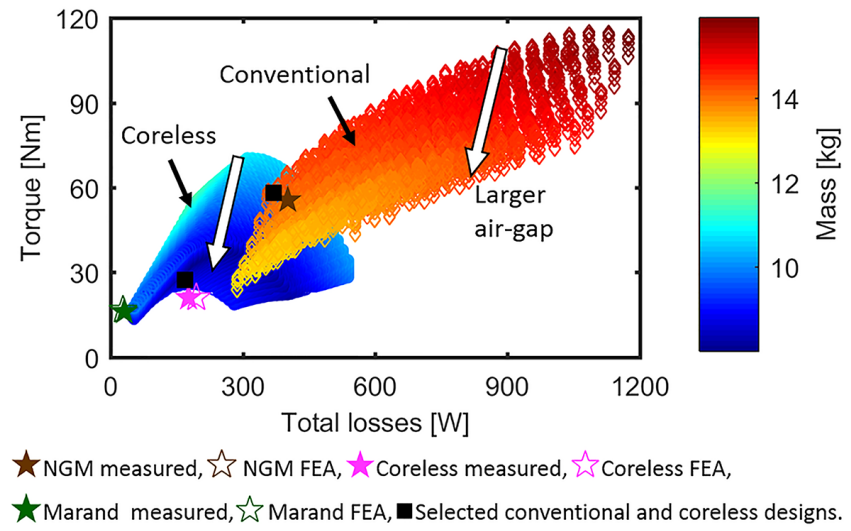

Figure 22. Torque versus total losses of conventional and coreless designs, compared to prototype and commercial machines employed in solar powered vehicles. Required torque is $56 \mathrm{Nm}$ for single active wheel or $28 \mathrm{Nm}$ for car designs with two active wheels, respectively.

hence the overall axial length is constant and fixed by the wheel dimensions. The maximum diameter available has been utilized to increase torque density. The identical wheel is used for configurations with single and double driving wheels.

\section{CONCLUSION}

A systematic comparative study for conventional and coreless AFPM machines for single and double driving wheel solar cars was presented. The parametric design study was conducted in order to select optimum designs, favoring lighter machines with higher efficiency and larger air-gap. Thousands of candidate designs have been analyzed for both configurations with the aid of a combined DOE and response surface methodology using FEA, which was validated on a laboratory prototype and on commercially available coreless and conventional machines commonly employed in the same application.

As part of the design methodology, a method for the calculation of the winding factor for air-gap concentrated windings was proposed. The differences in flux distribution in circumferential and axial directions, as well as coil pitch variations with radius were taken into account.

It is observed that for the space constraints under study and for a given cooling system, the torque generation by both machine types is limited, and this torque limit for conventional machine is at a higher value. This is due primarily to the higher air gap in coreless machines.

Coreless machines may therefore be more suitable for use in a two-wheel drive version, at the cost of slightly reduced 
efficiency, and larger overall mass as compared with single wheel drives. These limitations are offset by the better mass distribution achieved in two wheel drives, for which the conventional machine may not be suitable owing to large accumulated unsprung mass. Another advantage of a coreless AFPM construction is the limited investment required for stator tooling which is important when producing motors for the low volume solar car market.

Conventional AFPM topology could be used more efficiently with one driving wheel. The coreless machine may also be selected for single in-wheel configurations, although machine designs with very small air-gap are necessary to meet the torque requirement. Considering that the latest generation solar cars employ two-wheel drives, based on this study, it is recommended to consider the opportunities provided by coreless machine for such configurations.

\section{ACKNOWLEDGMENT}

The financial support of University of Kentucky, the L. Stanley Pigman endowment and the SPARK program, of ANSYS Inc. for the software and of Arnold Magnetic Technologies for building the PM prototype rotor is gratefully acknowledged. The authors also thank Professor J. F. Eastham of University of Bath and Mr. Chris Heintz of University of Kentucky for their contributions, including experimental data.

\section{REFERENCES}

[1] G. Heins, D. M. Ionel, D. Patterson, S. Stretz, and M. Thiele, "Combined experimental and numerical method for loss separation in permanentmagnet brushless machines," IEEE Transactions on Industry Applications, vol. 52, no. 2, pp. 1405-1412, March 2016.

[2] D. J. Patterson, J. L. Colton, B. Mularcik, B. J. Kennedy, S. Camilleri, and R. Rohoza, "A comparison of radial and axial flux structures in electrical machines," in 2009 IEEE International Electric Machines and Drives Conference, May 2009, pp. 1029-1035.

[3] A. G. Jack, B. C. Mecrow, G. Nord, and P. G. Dickinson, "Axial flux motors using compacted insulated iron powder and laminations - design and test results," in IEEE International Conference on Electric Machines and Drives, 2005., May 2005, pp. 378-385.

[4] D. Patterson and R. Spee, "The design and development of an axial flux permanent magnet brushless dc motor for wheel drive in a solar powered vehicle," IEEE Transactions on Industry Applications, vol. 31, no. 5, pp. 1054-1061, Sep 1995.

[5] A. Joss and P. J. Randewijk, "Design and optimisation of an ironless double-rotor radial flux permanent magnet machine," in 2016 XXII International Conference on Electrical Machines (ICEM), Sept 2016, pp. 1473-1479.

[6] A. Daghigh, H. Javadi, and H. Torkaman, "Design optimization of directcoupled ironless axial flux permanent magnet synchronous wind generator with low cost and high annual energy yield," IEEE Transactions on Magnetics, vol. 52, no. 9, pp. 1-11, Sept 2016.

[7] R.-J. Wang, M. J. Kamper, K. V. der Westhuizen, and J. F. Gieras, "Optimal design of a coreless stator axial flux permanent-magnet generator," IEEE Transactions on Magnetics, vol. 41, no. 1, pp. 55-64, Jan 2005.

[8] C. Schumann, T. Müller, E. Stein, and M. Pacas, "Axial-flux-machine with an ironless fractional slot winding," in IECON 2014 - 40th Annual Conference of the IEEE Industrial Electronics Society, Oct 2014, pp. 424-430.

[9] K. Latoufis, K. Troullaki, T. Pazios, and N. Hatziargyriou, "Design of axial flux permanent magnet generators using various magnetic materials in locally manufactured small wind turbines," in 2016 XXII International Conference on Electrical Machines (ICEM), Sept 2016, pp. 1545-1551.

[10] M. Chirca, S. Breban, C. A. Oprea, and M. M. Radulescu, "Analysis of innovative design variations for double-sided coreless-stator axialflux permanent-magnet generators in micro-wind power applications," in 2014 International Conference on Electrical Machines (ICEM), Sept 2014, pp. 385-389.
[11] M. Aydin, M. Gulec, Y. Demir, B. Akyuz, and E. Yolacan, "Design and validation of a 24-pole coreless axial flux permanent magnet motor for a solar powered vehicle," in 2016 XXII International Conference on Electrical Machines (ICEM), Sept 2016, pp. 1493-1498.

[12] H. C. Lovatt, V. S. Ramsden, and B. C. Mecrow, "Design of an in-wheel motor for a solar-powered electric vehicle," in 1997 Eighth International Conference on Electrical Machines and Drives (Conf. Publ. No. 444), Sep 1997, pp. 234-238.

[13] S. De, M. Rajne, S. Poosapati, C. Patel, and K. Gopakumar, "Lowinductance axial flux bldc motor drive for more electric aircraft," IET Power Electronics, vol. 5, no. 1, pp. 124-133, January 2012.

[14] R. J. Hill-Cottingham, P. C. Coles, J. F. Eastham, F. Profumo, A. Tenconi, and G. Gianolio, "Multi-disc axial flux stratospheric aircraft propeller drive," in Conference Record of the 2001 IEEE Industry Applications Conference. 36th IAS Annual Meeting (Cat. No.01CH37248), vol. 3, Sept 2001, pp. 1634-1639 vol.3.

[15] N. Taran, V. Rallabandi, G. Heins, and D. M. Ionel, "A comparative study of conventional and coreless axial flux permanent magnet synchronous motors for solar cars," in 2017 IEEE International Electric Machines and Drives Conference (IEMDC), May 2017, pp. 1-7.

[16] N. Taran, V. Rallabandi, D. M. Ionel, and G. Heins, "A comparative study of coreless and conventional axial flux permanent magnet synchronous machines for low and high speed operation," in 2017 IEEE Energy Conversion Congress and Exposition (ECCE), Oct 2017, pp. 321-327.

[17] NuGen Mobility Inc., "SCM150-XXX axial flux, brushless pm motor specifications," 2007.

[18] R. J. Hill-Cottingham, P. C. Coles, J. F. Eastham, F. Profumo, A. Tenconi, G. Gianolio, and M. Cerchio, "Plastic structure multi-disc axial flux pm motor," in Conference Record of the 2002 IEEE Industry Applications Conference. 37th IAS Annual Meeting (Cat. No.02CH37344), vol. 2, Oct 2002, pp. 1274-1280 vol.2.

[19] F. Profumo, A. Tenconi, M. Cerchio, J. F. Eastham, and P. C. Coles, "Axial flux plastic multi-disc brushless pm motors: performance assessment," in Applied Power Electronics Conference and Exposition, 2004 APEC '04. Nineteenth Annual IEEE, vol. 2, 2004, pp. 1117-1123 vol.2.

[20] M. J. Kamper, R. J. Wang, and F. G. Rossouw, "Analysis and performance of axial flux permanent-magnet machine with air-cored nonoverlapping concentrated stator windings," IEEE Transactions on Industry Applications, vol. 44, no. 5, pp. 1495-1504, Sept 2008.

[21] B. Xia, J. X. Shen, P. C. K. Luk, and W. Fei, "Comparative study of air-cored axial-flux permanent-magnet machines with different stator winding configurations," IEEE Transactions on Industrial Electronics, vol. 62, no. 2, pp. 846-856, Feb 2015.

[22] A. Mohammadpour, A. Gandhi, and L. Parsa, "Winding factor calculation for analysis of back emf waveform in air-core permanent magnet linear synchronous motors," IET Electric Power Applications, vol. 6, no. 5, pp. 253-259, May 2012

[23] S. G. Min and B. Sarlioglu, "Analytical calculation of back emf waveform for linear pm motors in slotted and slotless structures," IEEE Transactions on Magnetics, vol. 53, no. 12, pp. 1-10, Dec 2017.

[24] N. Chayopitak and D. G. Taylor, "Performance assessment of air-core linear permanent-magnet synchronous motors," IEEE Transactions on Magnetics, vol. 44, no. 10, pp. 2310-2316, Oct 2008.

[25] V. Rallabandi, N. Taran, and D. M. Ionel, "Multilayer concentrated windings for axial flux pm machines," IEEE Transactions on Magnetics, vol. 53, no. 6, pp. 1-4, June 2017.

[26] C. R. Sullivan, "Computationally efficient winding loss calculation with multiple windings, arbitrary waveforms, and two-dimensional or threedimensional field geometry," IEEE Transactions on Power Electronics, vol. 16, no. 1, pp. 142-150, Jan 2001.

[27] D. N. Mbidi, K. van der Westhuizen, R. Wang, M. J. Kamper, and J. Blom, "Mechanical design considerations of a double stage axialflux pm machine," in Conference Record of the 2000 IEEE Industry Applications Conference. Thirty-Fifth IAS Annual Meeting and World Conference on Industrial Applications of Electrical Energy (Cat. No.00CH37129), vol. 1, 2000, pp. 198-201 vol.1.

[28] Axial flux surface mount motor kit for solar vehicle applications, application notes. [Online]. Available: http://lati-solar-car.wikispaces.com/file/view/Application+Notes+ -+Surface+Mount+Kit+Motor+-+Augst+2011.pdf

[29] V. Rallabandi, N. Taran, D. M. Ionel, and J. F. Eastham, "On the feasibility of carbon nanotube windings for electrical machines case study for a coreless axial flux motor," in 2016 IEEE Energy Conversion Congress and Exposition (ECCE), Sept 2016, pp. 1-7. 
Narges Taran (S'16) received her M.S. degree in Power Electronics and Electric Machines from K. N. Toosi University of Technology, Tehran, Iran, in 2014. In 2016, she started her PhD studies at University of Kentucky, Lexington, $\mathrm{KY}$, were she is currently a $\mathrm{PhD}$ candidate. Her research focuses on electric machines, computational electromagnetics, optimization methodologies, and power electronic drives.

Vandana Rallabandi (M'17) is a Post-doctoral Researcher in the SPARK Laboratory, Electrical and Computer Engineering Department, University of Kentucky, Lexington, KY. Prior to this, she was a Research Engineer at the General Electric (GE) Global Research Center in Bangalore, India. She obtained the Masters and Ph.D. degrees at the Indian Institute of Technology Bombay, India. She has published over forty journal and conference proceedings papers, including three that received awards from IEEE, IET, and ICRERA, respectively, co-authored four book chapters, and has more than five invention disclosures and patent pending applications. She has been a reviewer for IEEE transactions on Industry Applications, Energy Conversion, Power Electronics, Industrial Electronics and Magnetics, IET Electric Power Applications and Electric Power Components and Systems. Her areas of work include electric machines, power electronics drives, renewable energy devices and systems, energy storage, and power systems.

Greg Heins (S'04-M'08) received the B.Eng. (Hons.) degree (Mechanical) and the University Medal from the University of New South Wales, Sydney, Australia, in 2000 and the Ph.D. degree from Charles Darwin University, Darwin, Australia, in 2008. He is currently the Head of Research and Development for Regal Beloit Corporation, Asia Pacific. He has previously worked as a Manufacturing Engineer with Robert Bosch Australia and as a Senior Lecturer at Charles Darwin University. In 2011 he was awarded an Australian Learning and Teaching Citation for Outstanding Contributions to Student Learning. His research interests include the design, control and manufacture of electric motors, vibration analysis, system modeling and identification.
Dan M. Ionel (M'91-SM'01-F'13) received the M.Eng. and Ph.D. degrees in electrical engineering from the Polytechnic University of Bucharest, Bucharest, Romania. His doctoral program included a Leverhulme Visiting Fellowship at the University of Bath, Bath, U.K. He was a Post-Doctora Researcher with the SPEED Laboratory, University of Glasgow, Glasgow, U.K.

He is currently Professor of Electrical Engineering and the L. Stanley Pigman Chair in Power with the University of Kentucky, Lexington, KY, where he also serves as the Director of the Power and Energy Institute of Kentucky (PEIK) and of the SPARK Laboratory. He previously worked in industry, most recently as a Chief Engineer with Regal Beloit, Corp., Grafton, WI, USA, and, before that, as the Chief Scientist for Vestas Wind Turbines. Concurrently, he also was a Visiting and Research Professor at the University of Wisconsin and Marquette University, Milwaukee, WI, USA. He contributed to technology developments with long lasting industrial impact, holds more than thirty patents, and published more than two hundred technical papers, including four that received IEEE awards.

Dr. Ionel was the inaugural Chair of the IEEE Industry Applications Society Renewable and Sustainable Energy Conversion Systems Committee and an Editor of the IEEE TRANSACTIONS ON SUSTAINABLE ENERGY $\mathrm{He}$ is the Editor in-Chief of the Electric Power Components and Systems Journal, the Past Chair of the IEEE Power and Energy Society Electric Motor Subcommittee, and was the General Chair of the IEEE 2017 Anniversary Edition of the International Conference on Electrical Machines and Drives. 